\title{
TINGKAT KECERDASAN ADVERSITY MAHASISWA PERANTAU DI MANADO
}

\author{
Aris Soleman \\ Program Studi Psikologi Islam, Institut Agama Islam Negeri Manado, Sulawesi Utara \\ E-mail: arissoleman@iain-manado.ac.id
}

\begin{abstract}
The overseas students will experience and face many changes (shock culture). They have to face the new environment, culture, and systems. For this reason, the overseas students need a high level of struggle and endurance in facing and solving challenges and problems occured. The purpose of this study was to measure and describe the adversity intelligence of overseas students in Manado. This research used a descriptive research with a quantitative approach. The population of this research was the overseas students in Manado. Furthermore, the samples taken were 100 students by the sampling technique using Quota Sampling. The technique for analyzing data was done by using the Ms. Excel program. The results showed that the majority of respondents were at a moderate level of Adversity intelligence. There are no respondents who have a high level of Adversity intelligence.
\end{abstract}

Keywords: Adversity Intelligence, the Overseas Students

\begin{abstract}
ABSTRAK
Mahasiswa perantau akan mengalami dan menghadapi banyak perubahan (shock culture). Mereka harus menghadapi lingkungan, budaya serta sistem yang baru. Untuk itu mahasiswa perantau membutuhkan daya juang serta daya tahan yang tinggi dalam menghadapi dan menyelesaikan tantangan dan permasalahan yang terjadi. Tujuan penelitian ini adalah untuk mengukur dan menggambarkan kecerdasan adversity mahasiswa perantau di kota Manado. Penelitian ini menggunakan tipe penelitian deskriptif dengan pendekatan kuantitatif. Populasi penelitian ini adalah mahasiswa perantau yang ada di kota Manado. Sedangkan sampel yang diambil adalah sebanyak 100 orang mahasiswa dengan teknik pengambilan sampel menggunakan Quota Sampling. Teknik untuk menganalisis data dilakukan dengan menggunakan program Ms. Excel. Hasil penelitian menunjukkan bahwa sebagian besar responden berada pada tingkat kecerdasan Adversity yang sedang. Tidak ada responden yang memiliki tingkat kecerdasan Adversity yang tinggi.
\end{abstract}

Kata kunci: Kecerdasan Adversity, Mahasiswa Perantau

\section{PENDAHULUAN}

Kurang meratanya akses Pendidikan

Tinggi di Indonesia terutama yang ada di berbagai daerah, mendorong terjadinya urbanisasi pelajar dan mahasiswa untuk pergi ke daerah lain guna mencari dan mendapatkan fasilitas pendidikan yang mereka butuhkan. Dari data yang di keluarkan oleh kementerian riset, teknologi dan pendidikan tinggi tahun 2017 terkait statistik pendidikan tinggi menunjukkan bahwa, kecenderung para calon Mahasiswa memilih Perguruan Tinggi yang 
ada di pulau Jawa begitu tinggi. Dari data tersebut menunjukkan di beberapa Provinsi, seperti di DKI Jakarta, Jawa Barat, Jawa Tengah, Yogyakarta dan Jawa Timur merupakan wilayah dengan jumlah perguruan tinggi serta jumlah mahasiswa terbanyak. Di wilayah lain seperti Sumatera, Kalimantan, Sulawesi, Maluku dan Papua, terdapat juga beberapa Perguruan Tinggi yang memiliki cukup banyak mahasiswa meskipun tidak sebanyak di Jawa (Statistik Pendidikan Tinggi, 2017).

Kurangnya pilihan Perguruan Tinggi di beberapa daerah di Indonesia menjadi penyebab banyak calon Mahasiswa yang rela berpindah mukim ke daerah lain untuk mendapatkan jurusan dan program studi yang mereka inginkan. Manado sebagai ibu kota di Sulawesi Utara merupakan daerah yang memiliki berbagai macam sarana dan fasilitas pendidikan yang cukup memadai dibandingkan daerah-daerah lain yang ada disekitarnya. Meskipun tak sebanyak kotakota besar di Jawa namun tercatat terdapat 33 perguruan tinggi (Universitas, sekolah tinggi dan akademi) baik Negeri maupun Swasta yang berdiri di wilayah kota Manado (www.pendaftaranmahasiswa.web.id., 2020). Hal tersebut membuat para calon Mahasiswa dari luar kota Manado tertarik untuk merantau dan menimba ilmu di kota tersebut.
Dalam penelitian ini, konsep mahasiswa perantauan menggunakan definisi Mochtar Naim yang menyebutkan bahwa merantau merupakan tipe khusus dari migrasi dengan konotasi budaya tersendiri yaitu seorang individu yang datang dari luar daerah, meninggalkan kampung halaman atau tanah kelahiran untuk pergi merantau ke kota, wilayah atau bahkan luar negeri, dengan kemauan sendiri, dalam kurun waktu tertentu/untuk jangka waktu lama atau tidak biasanya dengan maksud kembali pulang, dan dengan tujuan melanjutkan pendidikan ke jenjang perguruan tinggi. Berbagai alasan mengapa mereka melanjutkan studi diluar daerah, antara lain memperluas wawasan, memperoleh pendidikan yang lebih baik, memperoleh pengalaman baru dan mengharapkan tingkat kehidupan yang lebih baik (Naim, 1984).

Namun banyak tantangan dan rintangan yang harus dihadapi seorang mahasiswa saat menuntut ilmu di daerah lain. Mulai dari penyesuaian pola hidup, penyesuaian pola makan dan jenis makanan, hingga penyesuaian dengan orang dan lingkungan yang baru ia temui. Semuanya tampak mudah bagi sebagian Mahasiswa, namun terasa sulit bagi banyak Mahasiswa yang lain. Pada saat memasuki dunia kampus, Mahasiswa baru akan mengalami dan 
menghadapi banyak perubahan dan hal-hal baru (shock culture). Hal tersebut menuntut mereka untuk cepat beradaptasi dengan lingkungan, budaya serta sistem yang ada. Dimana penyesuaian diri yang dilakukan dapat berlangsung dengan mulus, tapi banyak juga kesulitan dan hambatan yang muncul. Menurut Gunarsa (2000) kesulitan penyesuaian diri pada mahasiswa berkisar pada perbedaan sifat pendidikan di SLTA dan Perguruan Tinggi/Akademi (kurikulum, disiplin, hubungan antara dosen dengan mahasiswa), hubungan sosial, masalah ekonomi, pemilihan bidang studi atau jurusan, mencari tempat tinggal (kost/kontrakkan).

Penelitian yang dilakukan oleh Novia Karmiana (2015) pada 40 orang mahasiswa perantau di kota Lampung menunjukkan bahwa sebanyak 45\% mahasiswa perantau merasa sedih dan rindu dengan keluarga yang ada di kampung halaman. Selain itu, ketakutan dan kesepian juga dirasakan oleh mahasiswa/mahasiswi perantauan tersebut ketika pertama kali tinggal jauh dari orang tua. Kemudian, sebanyak $30 \%$ mahasiswa perantau mengatakan bahwa perbedaan bahasa merupakan perbedaan yang paling utama dirasakan ketika pertama kali tinggal di perantauan. Ketika di kampung halaman, bahasa yang digunakan sehari-hari adalah bahasa daerah, sedangkan ketika di perantauan bahasa yang digunakan yaitu bahasa jawa dan indonesia. Hal tersebut menjadi kendala dalam berinteraksi dan berkomunikasi. Selain itu, sebanyak $17,5 \%$ mahasiswa mengatakan makanan menjadi salah satu yang harus dihadapi ketika di perantauan, karena makanan di Jawa yang manis berbeda dengan makanan di sumatra yang terasa pedas dan tidak perlu mencari karena ketika dirumah makanan sudah disediakan ibu dirumah. Terakhir di temukan sebanyak 7,5\% mahasiswa merasa tidak betah karena belum memiliki teman dekat di perantauan.

Untuk mengatasi dan memperbaiki kesulitan serta masalah yang dihadapi mahasiswa perantau seperti pada hasil penelitian di atas, maka para mahasiswa perantau membutuhkan daya juang serta daya tahan yang tinggi. Hal tersebut penting dimiliki agar mereka tidak mudah menyerah dan putus asa dalam menjalankan kehidupan serta aktivitas perkuliahaannya. Daya juang yang ada dalam diri individu dapat terlihat dengan adanya sifat pengendalian dan penyesuaian diri akan situasi yang mempengaruhi berbagai bidang kehidupan. Pengendalian dan penyesuaian diri dapat memotivasi seseorang untuk berprestasi dan bersaing dalam mencapai kesuksesan (Stoltz, 2000). 


\section{METODE PENELITIAN}

Penelitian ini menggunakan tipe penelitian deskriptif dengan pendekatan kuantitatif. Menurut Sugiyono penelitian deskriptif yaitu, penelitian yang dilakukan untuk mengetahui nilai variabel mandiri, baik satu variabel atau lebih (independen) tanpa membuat perbandingan, atau menghubungkan dengan variabel yang lain. Metode penelitian kuantitatif, sebagaimana dikemukakan oleh Sugiyono adalah metode penelitian yang berlandaskan pada filsafat positivisme, digunakan untuk meneliti pada populasi atau sampel tertentu, pengumpulan data menggunakan instrumen penelitian, analisis data bersifat kuantitatif/statistik, dengan tujuan untuk menguji hipotesis yang telah ditetapkan. (Sugiyono, 2011).

Penelitian deskriptif kuantitatif merupakan data yang diperoleh dari sampel populasi penelitian dianalisis sesuai dengan metode statistik yang digunakan. Penelitian deskriptif dalam penelitian ini dimaksudkan untuk mendapatkan gambaran dan keteranganketerangan mengenai kecerdasan adversity pada mahasiswa perantau di kota Manado.

Populasi dalam penelitian ini adalah mahasiswa perantau yang ada di kota Manado. Sedangkan sampel yang diambil adalah sebanyak 100 orang mahasiswa. Teknik pengambilan sampel dari populasi dalam penelitian ini menggunakan Quota Sampling. Menurut Sugiyono (2011), sampling kuota adalah teknik untuk menentukan sampel dari populasi yang mempunyai ciri-ciri tertentu sampai jumlah (kuota) yang diinginkan. Dalam teknik ini jumlah populasi tidak diperhitungkan akan tetapi diklasifikasikan dalam beberapa kelompok. Sampel diambil dengan memberikan jatah atau quorum tertentu terhadap kelompok. Pengumpulan data dilakukan langsung pada unit sampling. Setelah kuota terpenuhi, pengumpulan data dihentikan. Dari populasi jumlah mahasiswa perantau yang begitu banyak dan dengan informasi data yang belum tersedia, membuat teknik sampling ini tepat untuk digunakan dalam penelitian ini.

Adapun instrumen penelitian yang digunakan dalam penelitian ini menggunakan kuesioner kecerdasan Adversity yang disusun berdasarkan 4 dimensi yang dikemukakan oleh Paul G. Stoltz yaitu; Control, OriginOwnership, Reach dan Endurance. (Stoltz, 2000).

Pada penelitian ini data diperoleh dengan mengantarkan dan menyebarkan langsung kuesioner kepada responden yang berada di wilayah kota Manado. Penelitian ini difokuskan pada beberapa kecamatan yang terdapat institusi pendidikan tinggi seperti Universitas, Akademi dan sebaginya. 
Beberapa kecamatan tersebut yaitu, kecamatan Paal 2, kecamatan Sario dan kecamatan Mapanget. Penyebaran kuesioner pada wilayah-wilayah tersebut dilakukan dengan menyebarkan 100 kuesioner. Setiap kuesioner diberikan kepada responden dengan terlebih dahulu mengkonfirmasi biodata responden terkait tempat tinggal dan status kemahasiswaannya.

\section{HASIL DAN PEMBAHASAN}

Hasil skor kecerdasan adversity dikategorisasikan menjadi tiga kagetori yaitu tinggi, sedang, dan rendah. Adapun frekuesi tingkat kecerdasan adversity mahasiswa perantau di kota Manado sebagai berikut:

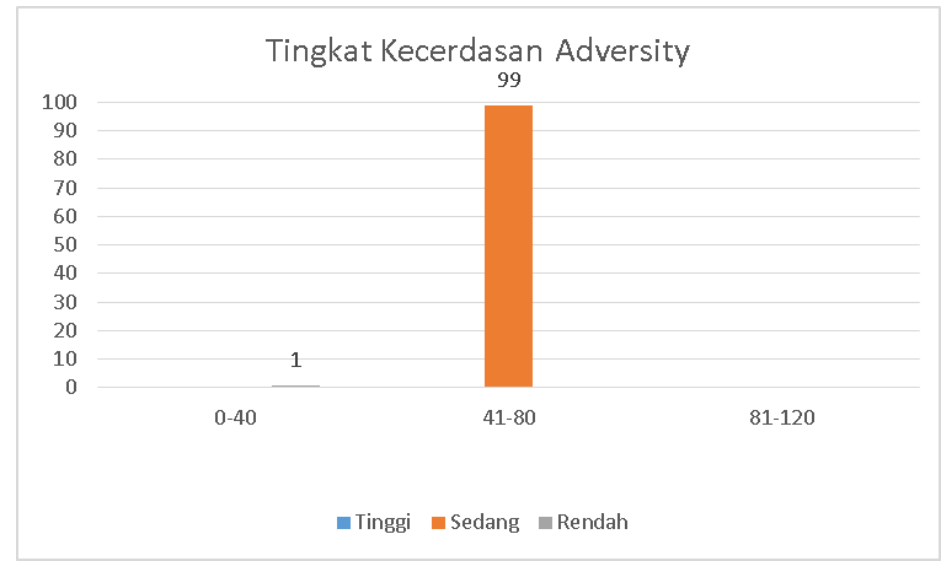

Gambar 1. Frekuensi data tingkat kecerdasan Adversity

Ditinjau dari data frekuensi, dapat diketahui bahwa tingkat kecerdasan adversity pada mahasiswa perantau di kota Manado dengan kategori sedang terlihat sebanyak 99 orang mahasiswa, kategori rendah hanya 1 orang mahasiswa dan tidak ada mahasiswa yang masuk dalam kategori tinggi. Dari 100 kuesioner yang diolah, gambaran umum mengenai responden berdasarkan jenis kelamin para responden, total jumlah laki-laki sebanyak 43 responden dan perempuan sebanyak 57 responden, artinya sebagian besar responden berstatus Mahasiswi.

Kategori sedang dapat di masukkan dalam kategori Campers dengan rentang skor 41-80 yaitu orang-orang yang mudah puas dengan hasil yang diperolehnya. Orang-orang dengan kategori Campers tidak ingin melanjutkan usahanya untuk mendapatkan lebih dari yang didapatkan sekarang. Di sini mereka mengakhiri usahanya karena sudah merasa puas dengan hasil yang didapat. Akan tetapi, Campers sudah berani menanggapi 
JIVA: Journal of Behaviour and Mental Health

Vol. 1, No. 1, Juli 2020, 8 - 17

tantangan dan mencapai titik tertentu. Mereka

Jika ditinjau skor data frekuensi dari yang termasuk dalam Campers mungkin tidak masing-masing aspek yang diukur dapat di menggunakan seluruh kemampuannya. lihat sebagai berikut:

Biasanya mereka mencari situasi aman.

a. Control

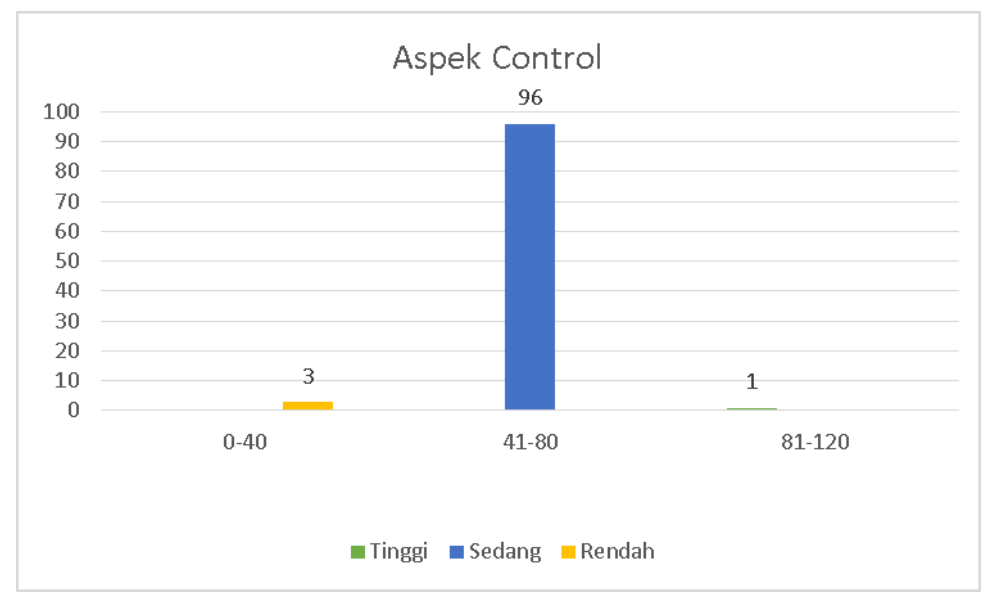

Gambar 2. Frekuensi data Aspek Control

Dalam aspek ini mengungkap berapa terlihat bahwa mahasiswa perantau memiliki banyak kendali yang seseorang rasakan kemampuan kendali yang sedang. Artinya terhadap sebuah peristiwa yang sulit. sebagian besar mahasiswa perantau di Manado Perbedaan antara respon adversity quotient cukup mampu mengatasi permasalahan yang yang rendah dan adversity quotient yang mereka temui meskipun jika dihadapkan pada tinggi adalah individu yang memiliki adversity permasalahan yang kompleks dan sulit untuk quotient tinggi akan merasakan kendali yang diselesaikan, mereka cenderung kurang dapat lebih besar atas peristiwa dalam hidup dari mengendalikannya dengan baik yang akhirnya pada yang memiliki adversity quotient rendah. berdampak pada perilaku dan performa Berdasarkan data frekuensi pada gambar 2, mereka. 


\section{b. Origin-Ownership}

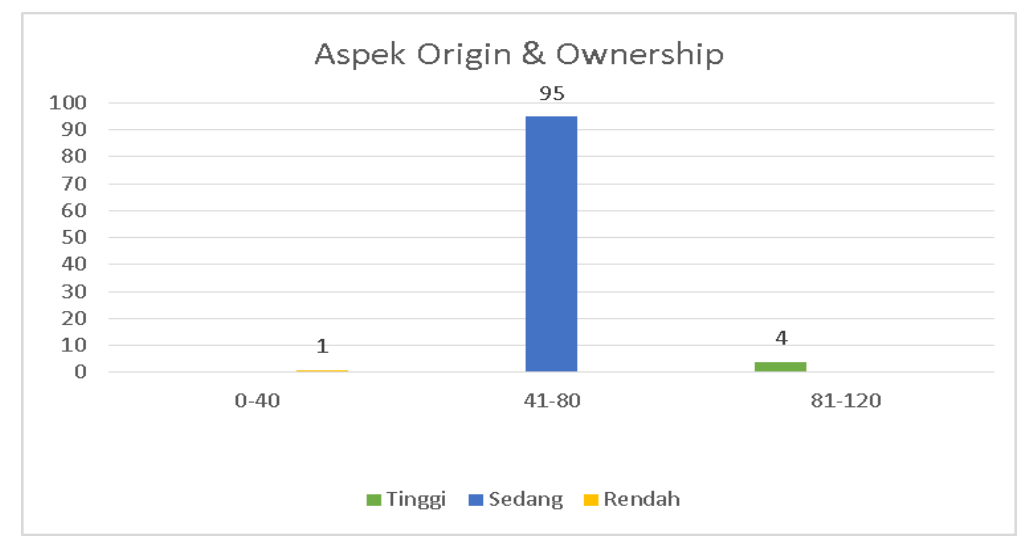

Gambar 3. Frekuensi data Aspek Origin \& Ownership

Aspek ini mengungkapkan siapa atau apa yang menjadi asal-usul kesulitan, dan menjelaskan bagaimana seseorang memandang sumber masalah yang ada. Apakah ia cenderung memandang masalah yang terjadi bersumber dari dirinya atau ada faktor-faktor lain diluar dirinya. Individu yang memiliki adversity quotient rendah cenderung melihat dirinya sendiri sebagai penyebab kesulitan. Ownership menyatakan individu tidak terlalu menyalahkan diri sendiri, tetapi tetap merasa bertanggung jawab untuk mengatasi kesulitan yang dialami. Jika dilihat dari data frekuensi pada gambar 3 di atas maka dapat disimpulkan bahwa mahasiswa perantau di Manado memiliki tingkat originOwnership yang sedang. Artinya mereka masih mempermasalahkan penyebab dari sebuah kejadian yang menimpanya dan cenderung menyalahkan hal diluar dirinya atau dirinya sendiri. Mereka juga cenderung mencari situasi aman dari suatu kejadian.

c. Reach

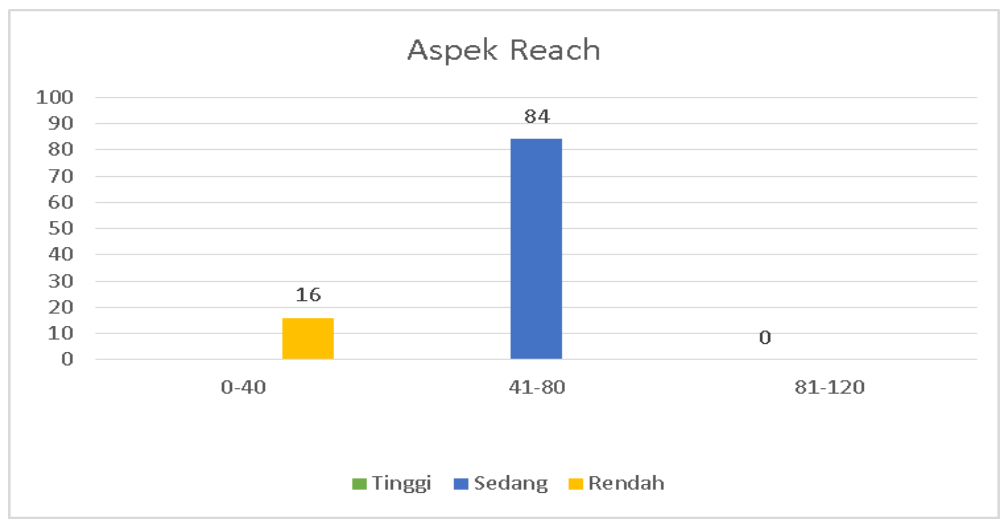

Gambar 4. Frekuensi data Aspek Reach 
Aspek ini mempertanyakan sejauh mana kesulitan akan menjangkau bagianbagian lain dari kehidupan individu. Responrespon dengan adversity quotient rendah akan membuat kesulitan memasuki segi-segi lain dari kehidupan seseorang. Semakin rendah skor R, semakin besar kemungkinan individu menganggap peristiwa-peristiwa buruk sebagai bencana. Semakin tinggi skor R, maka semakin besar kemungkinan individu membatasi jangkauan masalahnya pada peristiwa yang dihadapi. Dari gambar 4 di atas terlihat bahwa ada 16 responden mahasiswa yang memiliki skor yang rendah. Artinya mereka mudah terpengaruh oleh permasalahan-permasalahan yang terjadi sehingga dapat mempengaruhi bagian kehidupan mereka yang lain. Mereka cenderung menganggap permasalahan sebagai akhir dari tindakan mereka dan kurang terbuka untuk mengambil hikmah dari permasalahan tersebut untuk merubahnya menjadi hal yang lebih baik.

d. Endureance

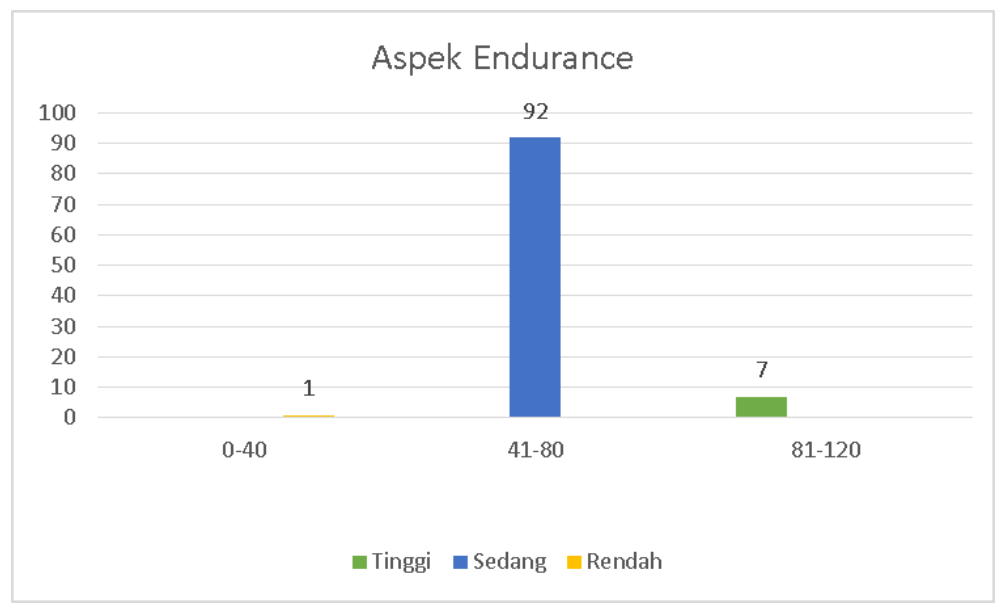

Gambar 5. Frekuensi Aspek Endurance

Dalam aspek ini mempertanyakan dua hal yang berkaitan yaitu, berapa lamakah kesulitan akan berlangsung, dan berapa lamakah penyebab kesulitan itu akan berlangsung. Semakin rendah skor E, semakin besar kemungkinan individu menganggap kesulitan dan penyebab-penyebabnya akan berlangsung lama. Individu yang melihat kemampuannya sebagai penyebab kegagalan cenderung kurang bertahan dibandingkan dengan orang yang mengaitkan kegagalan dengan usaha yang mereka lakukan. Dari 
gambar 5 di atas terlihat bahwa sebagian besar mahasiswa perantau di Manado memiliki daya tahan yang cukup baik dalam menghadapi suatu permasalahan. Ada 7 responden yang memiliki skor yang tinggi. Artinya mereka mampu bertahan dalam kesulitan dan selalu berusaha untuk keluar dari kesulitan tersebut.

\section{PENUTUP}

Berdasarkan hasil analisis data dan pembahasan, maka kesimpulan yang dapat diambil dari penelitian ini adalah tingkat kecerdasan adversity mahasiswa perantau di kota Manado berada pada kategori sedang atau kategori Campers. Aspek Reach memiliki rata-rata skor tertinggi di banding aspek yang lain.

Berdasarkan penelitian ini, peneliti menyadari bahwa masih terdapat banyak kekurangan di dalamnya dikarenakan adanya beberapa hambatan dan rintangan yang dialami. Untuk itu, terdapat beberapa saran yang bisa menjadi bahan pertimbangan sebagai penyempurnaan berbagai hal yang berkaitan dengan penelitian ini, yaitu:

1. Untuk penelitian selanjutnya, sebaiknya lebih banyak dalam pengambilan sampel, sehingga mendapatkan informasi yang lebih komprehensif.
2. Untuk penelitian selanjutnya dapat menambah variable lain dengan jenis penelitian korelasional atau jenis penelitian yang lain.

\section{DAFTAR PUSTAKA}

Creswell, J. W. (2009). Research Design: Qualitative, Quantitative, and Mixed Methods Approaches. Newbury Park: Sage Publications.

Gunarsa, D. S. (2000). Psikologi Parktis; Anak, Remaja dan Keluarga. Jakarta: PT. BPK Gunung Mulya.

Stoltz, P. G. (2000). Adversity Quotient, Mengubah Hambatan menjadi Peluang, Jakarta: PT. Gramedia Widiasarana Indonesia.

Sugiyono. (2011). Metode Penelitian Kuantitatif, Kualitatif dan $R \& D$. Bandung: Afabeta

Rany Fitriany. (2008). Hubungan Adversity Quotient (AQ) dengan Penyesuaian Diri Sosial Pada Mahasiswa Perantauan di UIN Syarif Hidayatullah Jakarta. Skripsi. Jakarta: UIN Syarif Hidayatullah.

Mochtar Naim. (1984). Merantau Pola Migrasi Suku Minangkabau. Yogyakarta: Gadjah Mada University Press.

Nuralisa, A., Machmuroch., Astriana, S. (2016). Hubungan antara Adversity Quotient dan Dukungan Sosial Teman Sebaya dengan Penyesuaian Diri Mahasiswa Perantauan Tahun Pertama Fakultas Teknik Universitas Sebelas Maret Surakarta. Jurnal Wacana, Vol 8, No 15.

Kementerian Riset, Teknologi dan Pendidikan Tinggi Republik Indonesia. (2017). Buku Statistik Perguruan Tinggi. Jakarta: Pusat Data dan Informasi Iptek Dikti. 
JIVA: Journal of Behaviour and Mental Health

Vol. 1, No. 1, Juli 2020, 8 - 17

Pendaftaran Perguruan Tinggi. (2020). Daftar Perguruan Tinggi Negeri/Swasta di Sulawesi Utara.

https://www.pendaftaranmahasiswa.w eb.id/2019/07/daftar-perguruantinggi-negeri-swasta_25.html Diakses tanggal 15 Januari 2020 